Revista de

Contabilidade e

Organizações

www.rco.usp.br
DOI: http://dx.doi.org/10.11606/issn.1982-6486.rco.2019.162327
Journal of

Accounting and

Organizations

\title{
Reconhecimento contábil nas operações em florestas nativas: o Caso Agrocortex
}

\author{
Accounting recognition in native forest operations: The Agrocortex Case
}

Phillemon Telêmaco da Graça ${ }^{\mathrm{a}}$, Marta Cristina Pelucio Grecco ${ }^{\mathrm{a}}$, George Andre Willrich Sales ${ }^{\mathrm{a}}$

${ }^{a}$ Faculddade FIPECAFI

Palavras-chave

Ativos biológicos.

CPC 29.

CPC 23.

Florestas nativas.

Manejo florestal sustentável.
Keywords

Biological assets.

IAS 41.

IAS 8 .

Native forest.

Sustainable forest management.
Informações do artigo

Recebido: 17 de setembro de 2019

Aprovado: 17 de dezembro de 2019

Publicado: 19 de dezembro 2019

\section{Resumo}

O objetivo desse artigo foi analisar e propor uma solução para o reconhecimento contábil de operações em florestas nativas com base no caso Agrocortex. A empresa Agrocortex explora uma floresta nativa na região amazônica e sua operação está fora do escopo das normas contábeis, por isso suas demonstrações contábeis foram elaboradas sem reconhecimento das florestas nativas. Diante disso foi construída uma proposta de solução, pautada no CPC 23 - Políticas Contábeis, Mudança de Estimativa e Retificação de Erro, com duas vertentes: (1) elaboração de uma política contábil para que seja procedido o reconhecimento contábil das operações em florestas nativas de maneira semelhante às florestas plantadas, em conformidade com o CPC 29, com mensuração ao valor justo; e (2) elaboração do reconhecimento contábil nas operações em florestas nativas, por meio de manejo florestal sustentável, nas demonstrações contábeis. A segunda vertente é uma sugestão aos normatizadores e entidades da classe contábil, para que analisem, com base no caso demonstrado, os aspectos teóricos do reconhecimento contábil nas operações em florestas nativas, por meio de manejo florestal sustentável.

\begin{abstract}
The aim of this paper was to analyze and propose a solution for accounting recognition of native forest operations based on the Agrocortex case. Agrocortex operates a native forest in the Amazon region and its operation is outside the scope of accounting standards and its financial statements have been prepared without recognition of native forests. In view of this, a solution proposal was built, based on IAS 8 - Accounting Policies, Changes in Accounting Estimates and Errors, with two aspects: (1) elaboration of an accounting policy to proceed with the accounting recognition of operations in native forests of similar to planted forests, in accordance with IAS 41, with fair value measurement; and (2) elaboration of an accounting recognition for native forest operations through sustainable forest management in the financial statements. The second aspect is a suggestion to the regulators and entities of the accounting class, to analyze, based on the case shown, the theoretical aspects of accounting recognition in native forest operations, through sustainable forest management.
\end{abstract}

\section{Implicações práticas}

A proposta apresentada como resultado desse artigo auxilia auditores e contadores de empresas, que exploram florestas nativas, na discussão do reconhecimento e mensuração desses ativos. Auxilia também analistas, durante o processo de investigação das demonstrações contábeis desse tipo de empresas, e ainda normatizadores contábeis, em seus processos de revisão de normas sobre ativos biológicos. 


\section{INTRODUÇÃO}

A importância das florestas para a sociedade e o meio ambiente é de conhecimento comum, seja do ponto de vista climático, biológico ou até mesmo econômico, neste caso, para que as riquezas produzidas pela natureza sejam exploradas de forma racional e sustentável. Fujihara et al. (2009) destaca que as florestas possuem papel central para a manutenção das características biológicas e climáticas do planeta, que estão atreladas a nossa própria existência enquanto raça humana.

Do total de 463 milhões de hectares de florestas brasileiras (SFB, 2013, p. 25), 98,45\% são representados pelas florestas nativas, ou seja, $53,56 \%$ de todo o território brasileiro. Já as florestas plantadas, representam $1,55 \%$ do total, o que corresponde a $0,84 \%$ do território brasileiro. O Ministério do Meio Ambiente estima que $69 \%$ dessa cobertura florestal tenha potencial produtivo. Diante disso, é possível perceber que esse setor pode contribuir, de forma significativa, para o crescimento econômico nacional e para o desenvolvimento regional.

Em termos numéricos, de acordo com a Confederação Nacional da Indústria - CNI (2016), o faturamento do setor florestal em 2015 foi de R \$ 60,6 bilhões, o que representa 1,1\% do Produto Interno Bruto (PIB) nacional e 5,5\% do PIB industrial, contribuindo para a geração de 610 mil empregos diretos. No âmbito dos impostos, o setor gerou R $\$ 10,2$ bilhões em tributos federais, estaduais e municipais, o que corresponde a $0,8 \%$ do total de arrecadação nacional.

Dentro da Contabilidade, as florestas nativas, são comumente tratadas de acordo com o exposto no CPC 29 - Ativo Biológico e Produto Agrícola, correlato da norma IAS 41 Agriculture. O CPC 29 aborda o tratamento contábil aplicado às operações que envolvam o ativo biológico e o produto agrícola. Contudo, a exploração em florestas nativas possui algumas particularidades, que a diferencia das operações em floretas plantadas. Sendo que o processo de transformação biológica das florestas plantadas é iniciado após o plantio, e nas florestas nativas, como sua formação ocorreu de forma natural e as árvores selecionadas para corte já estão completamente formadas pela própria natureza, não existe a etapa do plantio e, portanto, a transformação biológica. Diante disso, de acordo com as normas contábeis vigentes, a operação em florestas nativas não deveria ser enquadrada como atividade agrícola.

$\mathrm{Na}$ inexistência de uma norma que aborde uma transação em específico, como é o caso das florestas nativas, o CPC 23 - Políticas Contábeis, Mudança de Estimativa e Retificação de Erro, correlato da norma IAS 8 - Accounting Policies, Changes in Accounting Estimates and Errors, define que a administração da empresa deve formular, baseado em julgamentos, uma política contábil que resulte em informações relevantes e confiáveis, capaz de refletir a essência econômica de suas operações.

Apesar da importância das florestas nativas, principalmente para o Brasil, a literatura contábil tem dispensado pouca atenção ao assunto (Herbohn \& Herbohn, 2006; Grege-Stalmane, 2010; Feleagã, Feleagã \& Raileanu, 2012; Fischer \& Marsh, 2013), e até o momento não há uma definição de qual o reconhecimento contábil adequado para suas operações.

Devido à ausência dessa informação nas demonstrações contábeis, as empresas que operam nesse segmento enfrentam problemas como, por exemplo: (i) alavancar-se por meio de empréstimos bancários, uma vez que o ativo biológico não é aceito como garantia pelas instituições financeiras por não estar registrado no ativo da empresa; (ii) contratar financiamentos direto com os fornecedores para aquisição de máquinas e equipamentos florestais, com taxas de juros muitas vezes superiores às exigidas das demais empresas pela falta de garantias; (iii) dificuldade por parte dos analistas de mercado e demais usuários da informação contábil, em visualizar a operação da empresa refletida nas demonstrações contábeis.

Aryanto (2013) destaca que o raciocínio generalizado da norma IAS 41, não abordando todos os tipos de ativos biológicos, produz consequências significativas na qualidade das demonstrações financeiras e distorcem a informação contábil. Hogg e Jöbstl (2008) destacam que apenas uma pequena parte das unidades de gestão florestal utilizam a informação contábil como suporte para a gestão, o que demonstra a perda de sua relevância para as entidades que operam em florestas nativas.

Por isso, o presente trabalho visa analisar e propor uma solução, com base no CPC 23, para o reconhecimento contábil de operações em florestas nativas. Para alcançar o objetivo proposto será apresentado e discutido o caso da empresa Agrocortex Florestas do Brasil, que realiza suas operações de extração de madeiras por meio de manejo florestal sustentável, em uma floresta nativa na região amazônica.

A pesquisa justifica-se pois o tema abordado tem potencial de contribuição prática aos profissionais da contabilidade, a partir da identificação de uma operação que não possui definição nos pronunciamentos e, que tem sido pouco explorada na literatura contábil nacional e internacional. 
As contribuições esperadas com o resultado dessa pesquisa são: (1) reunir evidências, pautadas na Teoria da Contabilidade, para que as operações em florestas nativas sejam devidamente reconhecidas nas demonstrações contábeis, por meio do manejo florestal sustentável, minimizando os problemas apontados no curso dos negócios da empresa; (2) demonstrar aos normatizadores que as operações em florestas nativas estão equivocadamente fora do escopo da norma contábil CPC 29; (3) fornecer orientações práticas aos profissionais da contabilidade e empresas que operam em florestas nativas e demais segmentos, em que suas operações estão às margens das normas de contabilidade; (4) despertar o interesse da comunidade acadêmica para a realização de pesquisas teóricas e práticas envolvendo os ativos biológicos, principalmente, no campo das florestas nativas.

\section{REFERENCIAL TEÓRICO}

\subsection{Ativo biológico}

De acordo com o Pronunciamento Conceitual Básico: "ativo é um recurso controlado pela entidade como resultado de eventos passados e do qual se espera que fluam futuros benefícios econômicos para a entidade" (CPC, 2011).

O CPC 29 define o ativo biológico como um animal e/ou uma planta, vivos. Da mesma forma, conceitua o produto agrícola como produto colhido de ativo biológico da entidade. Frisa-se a necessidade de distinção entre o ativo biológico e o produto agrícola. $\mathrm{O}$ ativo biológico pode ser entendido como o formador do produto agrícola, que por sua vez, forma o produto resultante após a colheita.

A atividade agrícola é um dos pontos essenciais para que se compreenda a abrangência do ativo biológico. Para o CPC 29, atividade agrícola é o gerenciamento da transformação biológica e da colheita de ativos biológicos para venda ou para conversão em produtos agrícolas ou em ativos biológicos adicionais, pela entidade. Uma vez que a atividade agrícola contempla uma série de atividades, o CPC 29 destaca algumas características dessa atividade: (a) capacidade de mudança; (b) gerenciamento de mudança; e (c) mensuração da mudança. É importante ainda destacar que uma das principais características do ativo biológico, é a transformação biológica.

A capacidade de mudança da atividade agrícola, por sua vez, resulta dos seguintes eventos: (a) crescimento, caracterizado pelo aumento em quantidade ou melhoria na qualidade do animal ou planta; degeneração, sendo a redução na quantidade ou deterioração na qualidade de animal ou planta; ou procriação caracterizada pela geração adicional de animais ou plantas; ou (b) produção de produtos agrícolas, tais como látex, folhas de chá, lã, leite. Martins, Gelbcke, Santos e Iudícibus (2013, p. 327) destacam que “[...] a atividade agrícola pressupõe a gestão das transformações biológicas, não estando enquadradas, por exemplo, atividades de pesca no oceano ou desflorestamento".

O reconhecimento é parte integrante das fases que compõem o processo contábil, e sua aplicabilidade está condicionada ao atendimento dos requisitos da definição conceitual do elemento que se almeja reconhecer. No caso do reconhecimento de um ativo, o item a ser reconhecido deve atender às definições conceituais de ativo, discutidas e apresentadas anteriormente. O processo de reconhecimento contábil do ativo biológico é bastante semelhante ao de qualquer outro ativo, devendo ser reconhecido somente quando a entidade controla o ativo como resultado de eventos passados, em que seja provável a obtenção de benefícios econômicos futuros com seu valor justo ou custo mensurado confiavelmente.

Referente ao controle, o CPC 29 destaca que em atividade agrícola, o controle pode ser evidenciado, por exemplo, pela propriedade legal do gado e a sua marcação no momento da aquisição, nascimento ou época de desmama. Os benefícios econômicos futuros são, normalmente, determinados pela mensuração dos atributos físicos significativos. Amaro, Souza e Silva (2016, p.3) observaram que existe uma lacuna entre a norma estabelecida pelo CPC 29 e o reconhecimento e a mensuração dos ativos biológicos divulgados pelas empresas brasileiras. Por isso, é necessário investigar questões que envolvem o reconhecimento contábil dos ativos biológicos, a fim de que as normas sejam mais bem compreendidas, aplicadas e discutidas pela comunidade contábil.

Uma dessas questões é o reconhecimento contábil das operações em floretas nativas, por meio do manejo florestal sustentável. Tal reconhecimento ainda gera dúvidas aos profissionais dentro das demonstrações contábeis, uma vez que as normas contábeis vigentes - CPC 29 e IAS 41 - não abordam de forma clara a questão da exploração de florestas nativas (florestas não plantadas). Faz-se necessário, portanto, recorrer à teoria da contabilidade que, segundo Hendriksen e Van Breda (1999), oferece uma compreensão melhor e um referencial conceitual para a avaliação das práticas existentes, além de orientar o desenvolvimento de novas práticas e procedimentos. 
Hogg e Jöbstl (2008) citam que os ativos florestais são o ponto fraco da contabilidade nas empresas do setor. Para os autores, essa contabilidade não está totalmente desenvolvida e nem é suficientemente utilizada como suporte para o gerenciamento. Aryanto (2013) traz algumas críticas às normas IFRS e especificamente ao IAS 41 em sua aplicação, afirmando que a norma está centrada em certos tipos de ativos biológicos, existentes apenas em alguns países específicos.

No tocante à mensuração do ativo biológico, o CPC 29, em seu item 13, destaca que o ativo biológico deve ser mensurado ao valor justo menos a despesa de venda no momento do reconhecimento inicial e no final de cada período de competência, exceto para os casos descritos no item 30, em que o valor justo não possa ser mensurado de forma confiável. Rech e Pereira (2012, p. 132) chamam a atenção para o quesito da subjetividade da informação afirmando que "nem todos os ativos possuem um mercado ativo e, consequentemente, valor de mercado, o que, além de dificultar a sua mensuração, esta torna-se subjetiva”.

A definição de valor justo está descrita no CPC 29 como: "preço que seria recebido pela venda de um ativo ou que seria pago pela transferência de um passivo em uma transação não forçada entre participantes do mercado na data de mensuração" (item 8). Martins et al (2013, p. 329) afirmam que os conceitos e definições sobre o valor justo constantes no CPC 29 são, na essência, os mesmos presentes na norma internacional sobre o assunto, IFRS 13 - Fair Value Measurements, correlata do CPC 46 - Mensuração do valor justo.

Considerando que os ativos biológicos estão sujeitos à transformação biológica, processo que compreende o crescimento, degeneração e procriação, que causam mudanças quantitativas e qualitativas em suas formas físicas, a sua mensuração ao valor de custo, como ocorria na contabilidade tradicional, antes da entrada em vigor do CPC 29, reproduzia informações passíveis de questionamentos quanto a sua capacidade de representar a realidade econômica. Nesse sentido, a adoção do valor justo para os ativos biológicos representa uma aproximação direta com as mudanças no estado físico desses ativos, ou seja, na medida em que ocorrem as transformações biológicas gera-se valor aos ativos biológicos.

Para mensuração a valor justo, o CPC 46 traz uma hierarquia a ser seguida para a determinação do valor, sendo composta por: nível 1, preços cotados não ajustados; nível 2, informações observáveis direta ou indiretamente, não incluídas no nível 1 (ajustadas); e nível 3, com utilização de dados não observáveis, mantendo as premissas dos participantes do mercado.

Os ativos biológicos, geralmente, classificam-se no nível 3, uma vez que sua mensuração ocorre durante o processo da transformação biológica, que causam mudanças quantitativas e qualitativas nesses ativos, com isso, faz-se necessário a utilização de projeções financeiras, baseadas em estimativas, para a obtenção dos valores adicionados pelas mudanças no ativo biológico. Tal fato foi constatado por Amaro, Souza e Silva (2016). Os autores, ao analisarem 35 empresas no período de 2010 a 2015, verificaram que todas utilizavam o método da receita (fluxos de caixa futuros descontados a valor presente), caracterizando informações obtidas no nível 3.

\subsection{As operações florestais nas normas contábeis}

O CPC 29 e a IAS 41 não tratam de forma separada as operações em florestas nativas (florestas não plantadas), e os exemplos citados nas normas aplicam-se estritamente às florestas plantadas. A norma norte americana de contabilidade Accounting Standards Codification 905 Agriculture - emitida pelo FASB, que trata do reconhecimento contábil em operações florestais, também faz menção a uma operação em florestas plantadas.

Em um estudo comparativo entre as normas estadunidenses Generally Accepted Accounting Principles (US GAAP) e as IFRS sobre ativos biológicos, Fischer e Marsh (2013, p.68) mostram que, geralmente, a orientação de reconhecimento e relatórios agrícolas dos EUA contém menos informações e, portanto, é menos benéfica para os usuários das demonstrações financeiras. Os autores ainda constataram que as normas estadunidenses possuem um caráter mais conservador para o reconhecimento e divulgação dos ativos agrícolas do que as normas IFRS.

Cabe destacar que, no âmbito internacional, a norma IAS 41 tem sido usada como referência para as operações florestais. No entanto, em seu estudo, Herbohn e Herbohn (2006), apontam que a referida norma é demasiadamente acadêmica e não tem foco nos aspectos práticos para auxiliar as empresas no reporte dos ativos biológicos, não sendo capaz de acomodar todas as operações que envolvam as atividades agrícolas.

Uma das limitações da IAS 41 está relacionada à própria definição de ativos biológicos, que conceitua apenas como animal e/ou planta, vivos. Nota-se que ao levar em conta essa definição, não considerou o reino dos fungos e o reino monera (bactérias), com isso, o cultivo de cogumelos, que são produzidos para comercialização, está fora da definição da norma IAS 41. Outra limitação da norma diz respeito ao tratamento das florestas nativas, uma vez que aborda apenas as questões referentes aos processos em florestas plantadas. 
Analisando os itens que se relacionam com a operação florestal, objeto dessa pesquisa, nas normas do IASB, FASB e CPC, pode-se verificar que em todos os casos, as referências são direcionadas exclusivamente às operações com florestas plantadas. Ou seja, em nenhum momento foram mencionados exemplos de florestas nativas, onde sua formação ocorreu de forma natural e sem intervenção da ação humana (replantio). Para Herbohn, Peterson e Herbohn (1998) as florestas nativas exigem uma atenção ainda maior nas questões contábeis, pois devido à beleza natural e diversidade biológica, incorpora benefícios comerciais e não comerciais, sendo que os benefícios não mercantis apresentam problemas metodológicos significativos.

A Austrália, por meio da Association of Consulting Foresters of Australia Division (ACFA), um órgão da estrutura do Institute of Foresters of Australia Limited (IFA), em uma iniciativa pioneira, emitiu em julho de 2012, o documento A Standard for Valuing Commercial Forests in Australia (Norma para valorização de florestas comerciais na Austrália). Essa norma foi elaborada com o objetivo de auxiliar as avaliações florestais para fins de relatórios financeiros, transações financeiras e gestão financeira, exigidos pela lei Corporations Act 2001 (lei das sociedades anônimas australiana) sobre as empresas que estão sujeitas às normas do Australian Accounting Standards Board (AASB), órgão responsável pela emissão das normas contábeis no país.

A norma do ACFA, em seu objetivo, reforça que se aplica apenas às propriedades florestais que forneçam bens e serviços estimados e comerciais. Ou seja, as empresas australianas que operam em florestas podem usar essa norma de valorização como referência no âmbito contábil. Um ponto a ser destacado nessa norma de valorização das florestas australianas é o tratamento diferenciado para o processo de transformação biológica, pois foi considerado explicitamente o processo de regeneração natural que ocorre, principalmente, em florestas nativas. Destaca o ACFA (2012), em seu item 2.3, que a transformação biológica compreende, entre outras coisas, a procriação (criação de árvores vivas adicionais, especialmente em uma floresta nativa ou contexto de regeneração natural).

A norma do ACFA trata da etapa de procriação dentro do processo de transformação biológica, associando-a a um processo que ocorre em florestas nativas, como é o caso da regeneração natural. A regeneração natural pode ser entendida como as árvores remanescentes que crescem ao entorno da área explorada por meio do manejo florestal sustentável. O plano de manejo condiciona a retirada de árvores por idade, ou seja, de maneira simples, só é possível extrair uma árvore em fase adulta, caso tenha outras árvores mais jovens da mesma espécie no entorno.

Embora seja uma norma para valorização de florestas, é importante salientar que caso haja exploração em florestas nativas as empresas australianas vão dispor de uma norma que orienta a valorização e, consequentemente, sinaliza que o reconhecimento contábil deve ser realizado. Nesse sentido, a Austrália deu um importante passo ao estabelecer a norma ACFA de valorização das florestas comerciais, tornando-se um exemplo interessante, assim como base de apoio, para que se estabeleça um vínculo direto com o reconhecimento contábil nas operações em florestas nativas por meio de manejo florestal sustentável.

O Manejo Florestal Sustentável se relaciona ao conceito de Exploração de Impacto Reduzido (EIR), que significa a extração planejada de apenas algumas árvores de um ecossistema. Balieiro et al. (2010, pg. 90) define a EIR como "um conjunto de técnicas de exploração que reduz os impactos da atividade, causados à vegetação residual, aos solos e a outros atributos ambientais da floresta, em comparação à exploração convencional".

No Brasil, a aprovação do Plano de Manejo Florestal Sustentável (PMFS), instrumento técnico que tem por objetivo o planejamento, coordenação, gestão e uso sustentável dos recursos naturais, é de competência exclusiva do Instituto Brasileiro do Meio Ambiente e dos Recursos Renováveis (IBAMA), conforme determinado pela Lei Federal Complementar n. 140/2011.

De acordo com o informativo técnico n.1 do Instituto Floresta Tropical (2014), alguns requisitos obrigatórios para a elaboração do PMFS incluem o inventário florestal amostral e o inventário contínuo. As etapas de inventário florestal amostral e o inventário contínuo evidenciam, de forma bastante clara e concisa, o controle e acompanhamento da transformação biológica durante todo o processo de exploração de uma floresta nativa. Nesse sentido, seria correto afirmar que, por meio das etapas de inventário amostral e inventário contínuo é possível gerenciar a transformação biológica, pois os processos de crescimento e regeneração da floresta são continuamente monitorados e constituem-se como uma obrigação aos detentores do PMFS.

Segundo o CPC 23 (2009) na ausência de política contábil às situações e eventos específicos, não enquadrados nos pronunciamentos contábeis existentes, a administração da empresa deve formular, baseados em julgamentos, uma política contábil que resulte em informações relevantes e confiáveis e que reflitam a essência econômica de transações, outros eventos e condições e, não, meramente a forma legal. 
Destaca-se, contudo, que antes da formulação de uma política contábil, a administração da empresa deve analisar minuciosamente em todo o regramento contábil, se não existem pronunciamentos, interpretações e orientações sobre o assunto. Para complementar, pode ser adotado, se for o caso, algum pronunciamento ou norma contábil por analogia com a operação da empresa.

Outro ponto que deve ser avaliado pela administração da empresa, refere-se ao uso de normas elaboradas por entidades que adotem estrutura semelhante à estrutura conceitual do CPC. Nesse sentido, Hendriksen e Van Breda (1999, pg. 168), já preconizavam tal questão ao afirmar que "tradicionalmente, a política contábil tem-se apoiado na prática geralmente aceita e na lógica indutiva-dedutiva visando restringir as áreas de divergência".

\section{PROCEDIMENTO METODOLÓGICO}

O procedimento metodológico desse estudo de caso segue as etapas delineadas por Lima, Antunes, Mendonça Neto e Peleias (2012) a partir de Yin (2005) e Stake (2005 apud Lima et al, 2012). Assim, primeiramente, foi formulado o problema: como reconhecer contabilmente as operações em florestas nativas por meio de manejo florestal sustentável?

Em seguida, foi necessário definir a unidade de caso. A empresa selecionada foi a Agrocortex Florestas do Brasil, que serviu para auxiliar no conhecimento sobre o problema, tratando-se, portanto, de um estudo de caso instrumental (Lima et al, 2012). Um dos autores é ex-funcionário da controladoria da empresa estudada, que autorizou o uso do nome da empresa em 27/4/17. Optou-se por usar um caso único, por se tratar de um caso peculiar, dessa forma, a pesquisa é caracterizada como exploratória (Lima et al, 2012).

O estudo foi desenvolvido a partir do seguinte protocolo: revisão da literatura apresentada no item 2 desse artigo; definição da empresa Agrocortex como unidade de caso; obtenção da autorização da empresa para o estudo; coleta de dados a partir das demonstrações contábeis publicadas, participação dos pesquisadores em reuniões com a gestão e com os auditores independentes para discussão do reconhecimento contábil, e com os engenheiros florestais para entendimento do processo do manejo florestal sustentável.

Os dados foram coletados junto aos gestores e engenheiros florestais nas dependências da empresa Agrocortex por meio de entrevistas realizadas presencialmente entre maio e setembro de 2017 por um dos autores desse artigo. Foram analisadas as demonstrações contábeis auditadas referente aos anos de 2014 e 2015 , em contraposição à revisão da literatura efetuada, com relação às florestas nativas e com os dados obtidos nas entrevistas junto aos gestores e engenheiros florestais. Um dos autores participou do processo de elaboração dessas demonstrações contábeis e das discussões com a auditoria, no período em que atuava na controladoria.

Por fim, o relatório final construído foi uma proposta de solução com base no que preconiza o CPC 23. A construção foi efetuada pela análise da operação de florestas nativas em comparação aos outros tipos de operações semelhantes, que resultou em um comparativo entre florestas nativas e florestas plantadas em seus processos de transformação biológica.

\section{O CASO AGROCORTEX FLORESTAS DO BRASIL S/A}

A Agrocortex pertence a um grupo de investidores de origem europeia que realizou altos investimentos no projeto de exploração florestal sustentável na região amazônica. A Agrocortex iniciou suas atividades empresariais no primeiro semestre de 2014, por meio de um contrato de parceria rural que concede à Agrocortex o direito de exploração florestal de uma área de aproximadamente 190 mil hectares por um prazo de 30 anos. $\mathrm{Na}$ impossibilidade de aquisição de terras na região amazônica, por empresas controladas por fundos de origem estrangeira, a empresa firmou um contrato de parceria rural com a empresa detentora das terras, bem como, a aquisição de $49 \%$ dessa mesma empresa. Contudo, mediante acordo entre as partes, todo o controle da operação ficou designado à Agrocortex. Ou seja, na essência, a Agrocortex exerce o controle e domínio de todos os aspectos da operação e deve efetuar um inventário amostral completo que permite avaliar, de forma balizada, a quantidade de madeira que poderá ser extraída ao longo do tempo. 
Antes de iniciar a operação, a cada ano, a Agrocortex tem a obrigação de realizar um inventário de $100 \%$ da área a ser explorada no ano. Com base nas informações desse inventário, identificam-se as espécies e as quantidades que deseja extrair e elabora-se um Plano de Operação Anual - POA e solicita-se a emissão para formalização da Autorização de Exploração - AUTEX ao IBAMA. A AUTEX limita-se a confirmar que o POA está de acordo com o PMFS - Plano de Manejo Florestal Sustentável inicial e que o determinado nesse PMFS será cumprido. Para evitar dúvidas, deve-se entender esta AUTEX como uma definição da quantidade de madeira passível de extração nesse ano, já que o IBAMA não tem poder de vetar a AUTEX, apenas de solicitar que se adeque ao PMFS, se for esse o caso, ratificando o volume da produção anual.

Após a etapa de extração, e uma vez que a Agrocortex tem uma operação verticalizada, as toras de madeira são transportadas para um complexo industrial madeireiro, de propriedade da Agrocortex, onde serão sujeitas a desdobro primário (corte em tábuas, lâminas e afins), incluindo o necessário processo de secagem das madeiras. Depois de seca, a madeira desdobrada será comercializada, preferencialmente no exterior.

A Agrocortex, é uma sociedade anônima de capital fechado e suas demonstrações contábeis são auditadas anualmente para fins de publicação. Nos anos de 2014 e 2015, durante os trabalhos de validação das demonstrações contábeis, houveram extensas discussões à respeito do reconhecimento do ativo biológico (floresta nativa) no Balanço Patrimonial da Agrocortex, uma vez que havia um entendimento de que as atividades da Agrocortex não compreendiam o gerenciamento do processo de crescimento, degeneração, produção e procriação, que causam as mudanças quantitativas e qualitativas no ativo biológico.

Os gestores da Agrocortex se reuniram diversas vezes com os auditores, inclusive com a presença de um engenheiro florestal, para demonstrar como ocorre o gerenciamento da transformação biológica em florestas nativas, porém, foi avaliado como a melhor alternativa para a situação, o não reconhecimento contábil do ativo biológico, uma vez que a norma contábil não aborda o assunto de forma clara o suficiente quando as operações ocorrem em florestas nativas, que tiveram a sua formação ocorrida naturalmente. Ademais, os auditores também propuseram em destacar o fato numa nota explicativa, onde foram mencionados os motivos que corroboraram para a conclusão do não reconhecimento contábil do ativo biológico da empresa Agrocortex.

Assim, durante os exercícios de 2014 e 2015, os usuários da informação contábil não visualizaram a operação da empresa - atividade de exploração em florestas nativas por meio do manejo florestal sustentável -, refletida nas demonstrações contábeis.

\subsection{Proposta de Solução com aplicação do CPC 23}

Conforme o Caso Agrocortex, bem como, as implicações do não reconhecimento contábil de suas operações, podemos afirmar que as demonstrações contábeis não atingiram o objetivo do relatório contábilfinanceiro de propósito geral, como determina a Estrutura Conceitual CPC 00 de representação fidedigna da situação financeira da entidade.

Nesse cenário, a alternativa válida para a solução da empresa estudada, seria a criação de uma política contábil, onde estarão formalmente definidas as regras e bases adotadas para a elaboração das demonstrações contábeis.

Considerando que o CPC 29 não aborda as questões referentes ao tratamento contábil das operações em florestas nativas (florestas não plantadas), uma vez que esta é uma norma que seria aplicável aos ativos biológicos, cabe o desenvolvimento de uma política contábil, baseada em julgamento de acordo com as orientações do CPC 23, para que se proceda o reconhecimento contábil de suas operações nas florestas nativas. Deve-se ainda divulgar de maneira clara todas as premissas adotadas que embasaram o julgamento.

Para o julgamento, foram consultados os engenheiros florestais, que destacaram os seguintes aspectos técnicos sobre os aspectos técnicos da transformação biológica e de seu gerenciamento:

a) Transformação biológica: O processo de transformação biológica em uma floresta nativa ocorre por meio das etapas de implantação, crescimento, degeneração e procriação, conforme Tabela 1, elaborada com auxílio dos engenheiros florestais. 
Tabela 1. Processo de transformação biológica em uma floresta nativa

\begin{tabular}{|c|c|c|}
\hline Etapas & Floresta plantada & Floresta natural \\
\hline Implantação & Artificial (plantio) & Natural (regeneração) \\
\hline Crescimento & $\begin{array}{l}\text { Inventário; } \\
\text { Desbaste, poda e adubação (ações para } \\
\text { favorecer o crescimento da árvore e a forma } \\
\text { do tronco) }\end{array}$ & $\begin{array}{l}\text { Inventário; } \\
\text { Tratamentos silviculturais (corte de cipós e árvores sem } \\
\text { interesse comercial, para favorecer árvores de interesse } \\
\text { comercial) }\end{array}$ \\
\hline Degeneração & $\begin{array}{l}\text { Colheita em área total (zera o "capital } \\
\text { natural" da referida floresta) }\end{array}$ & $\begin{array}{l}\text { Colheita seletiva (mantém estoque em diversas fases de } \\
\text { desenvolvimento - mudas, jovens, árvores passíveis de } \\
\text { corte e árvores velhas ou ocas) }\end{array}$ \\
\hline Procriação & $\begin{array}{l}\text { Artificial (produção em viveiros); } \\
\text { Fora da floresta (ex situ) }\end{array}$ & $\begin{array}{l}\text { Natural (árvores remanescentes produzem mudas); } \\
\text { Dentro da floresta (in situ) }\end{array}$ \\
\hline
\end{tabular}

Fonte: Elaborada pelos autores

b) Gerenciamento da transformação biológica: O processo de gerenciamento da transformação biológica ocorre pelo monitoramento de cada uma das etapas citadas no item a, garantindo o controle, acompanhamento e razoável segurança durante todo o processo.

Conforme demonstrado na Tabela 1, o processo e gerenciamento da transformação biológica ocorre tanto na floresta plantada, como na floresta nativa, com isso, não se recomenda ter tratamentos diferentes.

Dessa forma, a ausência do ativo biológico nas demonstrações contábeis, (i) causa uma afronta à teoria da contabilidade, uma vez que não atinge o objetivo da contabilidade de produzir informações confiáveis e relevantes para auxiliar seus usuários no processo de tomada de decisões, (ii) os investidores não compreendem a correta alocação de seus recursos, (iii) os credores não fornecem créditos e financiamentos, pois o ativo biológico poderia ser usado como garantia, entre outros.

Recomenda-se o reconhecimento da floresta nativa como ativo biológico, que deverá ser mensurado ao valor justo, tanto no reconhecimento inicial, bem como, nas suas respectivas variações, conforme as orientações que constam no CPC 29, em seu item 13. A mensuração ao valor justo deverá seguir os níveis hierárquicos definidos no CPC 46, discutidos no item 2.1 desse artigo.

Cabe ressaltar que, para Hogg e Jöbstl (2008) a norma internacional mudou a contabilidade agrícola de uma questão local para uma questão global. A mensuração ao valor justo em substituição à mensuração pelo custo histórico é benéfica, pois o custo histórico não reflete corretamente a realidade econômica da atividade agrícola. Da mesma maneira, a mensuração ao valor justo das florestas nativas refletirá mais adequadamente sua realidade econômica.

Para o caso da empresa Agrocortex, recomenda-se a elaboração de sua política contábil para tratamento das florestas nativas, redigida de acordo com os parâmetros estabelecidos pelo CPC23, onde serão estabelecidas as premissas e critérios para o reconhecimento contábil, bem como, a exposição dos motivos pelos quais a administração julga necessário formular a política contábil, com base nas recomendações efetuados nesse artigo.

\section{CONSIDERAÇÕES FINAIS}

O objetivo dessa pesquisa foi analisar e propor uma solução, com base no CPC 23, para o reconhecimento contábil de operações em florestas nativas com base no caso Agrocortex.

Conclui-se que as operações em florestas nativas deveriam ter tratamento contábil semelhante às florestas plantadas, com seu reconhecimento, mensuração e divulgação com base no CPC 29, uma vez que o processo de transformação biológica de ambos tipos de florestas ocorre por meio das etapas de implantação, crescimento, degeneração e procriação. Esse tratamento contábil atende: ao objetivo da contabilidade de produzir informações úteis e relevantes que auxiliem os seus usuários nos processos decisórios; e à representação fidedigna, que enfatiza a ideia de que a essência da operação deve prevalecer sobre a sua forma legal.

No tocante à sugestão aos normatizadores e demais entidades responsáveis por orientações e instruções técnicas em contabilidade, conclui-se que o caso demonstrado e estudado nessa pesquisa, pode contribuir como potencial referência para possíveis revisões, emissão de orientações, instruções e demais dispositivos que evidenciem a dimensão e consequências do não reconhecimento contábil das operações em florestas nativas, por meio do manejo florestal sustentável. 
Recomenda-se a ampliação do alcance do CPC 29 possibilitando melhor representação fidedigna e comparabilidade às informações contábeis de empresas que possuem operações em florestas nativas por meio do Manejo Florestal Sustentável estabelecendo comparabilidade às informações das empresas com operações em florestas plantadas. Como sugestão de pesquisa futura pode ser realizados estudos com o objetivo de verificar a ocorrência do não reconhecimento contábil em outras jurisdições. Outra sugestão de pesquisa futura, seria a realização de pesquisas quantitativas para análise de impactos nos valores de ativo, PL, lucratividade entre outros.

\section{REFERÊNCIAS}

Amaro, H. D., Souza, A., \& Silva, E. D. (2016). Ativo biológico: conceituação, reconhecimento e mensuração. XXIII Congresso Brasileiro de Custos.

Aryanto, Y. H. (2011). Theoretical Failure of IAS 41. Recuperado de https://ssrn.com/abstract=1808413 or

Balieiro, M. R., Espada, A. L. V., Nogueira, O., Palmieri, R., \& Lentini, M. (2010). As Concessões de Florestas Públicas na Amazônia Brasileira: Um manual para pequenos e médios produtores florestais. Piracicaba: Imaflora, SP; Belém: IFT, PA.

Confederação Nacional da Indústria [CNI]. (2016). Florestas e indústria: agenda de desenvolvimento. Brasília: CNI.

Comitê de Pronunciamentos Contábeis [CPC]. (2009). Pronunciamento Técnico n. 23 Políticas Contábeis, Mudança de Estimativa e Retificação de Erro. Recuperado dehttp://static.cpc.mediagroup.com.br/Documentos/296_ CPC_23_rev\%2003.pdf

. (2009). Pronunciamento Técnico n. 29 Ativo Biológico e Produto Agrícola. Recuperado dehttp://static. cpc.mediagroup.com.br/Documentos/324_CPC_29_rev\%2008.pdf.

- (2011). Pronunciamento Conceitual Básico (R1). Recuperado de http://www.cpc.org.br/CPC/ Documentos-Emitidos/Pronunciamentos/Pronunciamento? $\mathrm{Id}=80$.

Feleagã, L., Feleagã, N., \& Raileanu, V. (2012). Theoretical considerations about implementation of IAS 41 in Romania. Theoretical and Applied Economics 19(2), 31-38.

Fischer, M., \& Marsh, T. (2013). Biological Assets: Financial Recognition and Reporting Using US and International Accounting Guidance. Journal of Accounting and Finance 2(13), 57 - 74.

Fujihara, M.A., Cavalcanti, R., Guimarães, A., \& Garlipp, R. (2009). O valor das florestas. São Paulo: Terra das Artes Editora.

Grege-Stalmane, E. (2010). Challenges in accounting the forests - a Latvian case study. Annals of Forest Research $1(53), 53-58$.

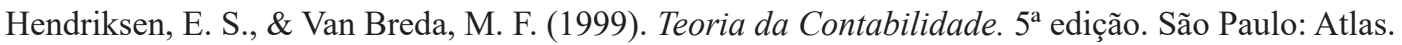

Herbohn, K., \& Herbohn, J. (2006). International Accounting Standard (IAS) 41: What Are the Implications for Reporting Forest Assets? Small-scale Forest Economics, Management and Policy, 5(2), 175 - 189. DOI: https://doi.org/10.1007/s11842-006-0009-1.

Peterson, R., \& Herbohn, J. L. (1998). Accounting for forestry assets: Current practice and future directions. Australian Accounting Review, 8(15), 54-66. DOI: https://doi.org/10.1111/j.1835-2561.1998. tb00080.x.

Hogg, J. N., \& Jöbstl, H. A. (2008). Developments in forestry business accounting and reporting: an international study. Austrian Journal of Forest Science. 125 (4), 219-250.

Instituto Floresta Tropical [IFT]. (2014) Manejo florestal e exploração de impacto reduzido em florestas naturais de produção da Amazônia. Informativo técnico n. 1. Recuperado de: http://ift.org.br/wp-content/ uploads/2014/11/Informativo-T\%C3\%A9cnico-1.pdf.

Lima, J. P. C., Antunes, M. T. P., de Mendonça Neto, O. R., \& Peleias, I. R. (2012). Estudos de caso e sua aplicação: proposta de um esquema teórico para pesquisas no campo da contabilidade. Revista de Contabilidade $e$ Organizações, 6(14), 127-144. DOI: https://doi.org/10.11606/rco.v6i14.45403.

Martins, E., Gelbcke, E. R., Santos, A. D., \& Iudícibus, S. D. (2013). Manual de contabilidade societária: aplicável a todas as sociedades: de acordo com as normas internacionais e do CPC. 
Rech, I. J., \& Pereira, I. V. (2012). Fair value: analysis of measurement methods applicable for fixed biological assets.Custose@gronegócio on line.8(2),131-157.

Serviço Florestal Brasileiro. (2013). Florestas do Brasil em resumo - 2013: dados de 2007-2012. Brasília: SFB. Disponível em http://www.florestal.gov.br/publicacoes/tecnico-cientifico/florestas-do-brasil-emresumo-2013

Yin, R. K. (2005). Estudo de caso: planejamento e métodos. 3. ed. Porto Alegre: Bookman.

\section{Como citar este artigo}

Graça, P. T. da, Grecco, M. C. P., \& Sales, G. A. W. (2019). Reconhecimento contábil nas operações em florestas nativas: o Caso Agrocortex. Revista de Contabilidade e Organizações, 13:e162327. DOI: http:// dx.doi.org/10.11606/issn.1982-6486.rco.2019.162327 